\title{
Design, characterization, and performance analysis of Miscanthus fiber reinforced composite for brake application
}

\author{
Mohamed KCHAOU***, Recai KUS***, D. Lenin SINGARAVELU**** and S. Mano HARAN***** \\ *Department of Mechanical Engineering, College of Engineering, University of Bisha, Saudi Arabia \\ **Laboratory of Electromechanical Systems (LASEM), National Engineering School of Sfax, University of Sfax, 3038 Sfax, Tunisia \\ ***Mechanical Engineering Dept., Technology Faculty, Selcuk University, Konya, Turkey \\ ****Department of Production Engineering, National Institute of Technology, Tiruchirappalli-620015, Tamil Nadu, India \\ *****Department of Mechanical Engineering, Surya Engineering College Mettukadai, Erode-638017 - India \\ *Corresponding Author: kchaou.mohamed@yahoo.fr
}

Submitted: $20 / 07 / 2020$

Revised: $17 / 11 / 2020$

Accepted: 23/11/2020

\begin{abstract}
This study deals with the development of new friction materials by incorporating Miscanthus fiber (5, 10, and 15 weight \%, noted Mat1, Mat2, and Mat3, respectively). The friction materials were tested for their physical, mechanical, and microstructural properties as per international standard. The performance analysis was carried out using Chase friction test rig. Results revealed that the biomass is beneficial with good fade, wear resistance, and recovery characteristics, with the same trend of other natural fibers. Therefore, this natural ingredient proved to be useful in the development of brake friction material.
\end{abstract}

Keywords: Brake system; Miscanthus fiber; Friction material; Tribological test; Performance.

\section{INTRODUCTION}

Nowadays, Asbestos is almost phased out in new generation of automotive brake friction materials, especially in the EU and US markets (Venkatesh et al., 2019) (Morshed et al., 2004). This is because the presence of asbestos in the industrial formulation has caused lung cancer and induced toxic and mutagenesis airborne particles (Wahlstrom et al., 2013). Several studies like Sai Balaji et al. (2013), Parandaman et al. (2015), and Aranganathan et al. (2016) have investigated possible development of friendlier friction materials by substituting Asbestos by Kevlar, glass fiber, or different types of graphite. In the last a few years, biomass has become an attractive reinforcement for friction composite from economic and ecological point of views (Jan, 2008). There is an increase in terms of environmental awareness in the world, which has aroused an interest in the research and the development of biodegradable and high-performance green materials (Ibhadode et al., 2008). Natural biomass for the application of braking can be obtained from vegetable, animal, or mineral resources. Along with the energy crisis and the ecologic risks, the natural fibers present several advantages such as abundance and nontoxicity as reported by Matějka et al. (2013) and Pujari et al. (2019). Up to now, the impacts of "natural asbestos" on braking performance and wear have been studied less compared to other asbestos. Knowing the strong potential of plant fibers, researchers have focused on possible potential and performance of these new ingredients. Shalwan and Yousif (2013) have developed a retrospective literature report about the use of natural ingredient in an industrial formulation with a special focus on their brake friction behavior. Idris et al. (2015) have produced ecofriendly brake pads using banana peels. Based on mechanical and tribological analysis, they concluded that an optimized formulation could show satisfactory performance for possible automotive braking 
application. Namessan et al. (2013) have investigated the effect of the incorporation of Hibiscus cannabinus fibers on a tribological behavior of a commercial formulation. Different chemical natural fiber treatments were tested to assure acceptable cohesion between natural and artificial ingredients. Koya and Fono (2010) have studied kernel shells-based composite. Satisfactory results are reported in concordance with the Standard Organization of Nigeria. Ibhadobe and Dagwa (2008) have developed asbestos-free friction lining materials from palm kernel shells. A comparative study with a commercial pad has shown a good trend between the chosen width percentage. More recently, Bashir et al. (2019) studied 3 banana fiber based green friction materials $(7,14$, and $21 \mathrm{wt} \%)$ at high temperature and high loading. The best combination, which has given the highest coefficient of friction, the best thermal stability, and the well fade behavior, consists of a mixture of $7 \%$ banana fiber to $28 \%$ phenolic resin binder. Singaravelu et al. (2019) discussed the possible use of treated and nontreated crab shell as the new ingredient to develop friction materials. Despite natural crab shell composite shows better thermal stability, the treated one had better fade and recovery characteristic, contributing to a performance friction composite material.

In this study, investigations on the use of Miscanthus fiber as reinforcement material in the friction composite are presented. The effect of varied weight percentage on the physical and mechanical properties is discussed. Performance characteristics of the friction composite are evaluated for possible use as brake lining material.

\section{MATERIALS AND METHODS MATERIALS}

Used as a plant fiber (Fig. 1a), Miscanthus had a density of $70 \mathrm{~kg} / \mathrm{m}^{3}$. The strain and stress at failure of Miscanthus were $4.3 \%$ and 95 to $118 \mathrm{MPa}$, respectively. It consists of $44 \%$ cellulose, $24 \%$ Hemicellulose, $17 \%$ Lignin, $1.5 \%$ Ash, and 13.5 other elements. In our case, Miscanthus fibers are chemically treated prior to their utilization for the preparation of the green composite with the aim of improving their interfacial bonding with phenolic resin. As described by Kabir et al. (2012), fibers are first dried at $80^{\circ} \mathrm{C}$ for $30 \mathrm{~min}$, then introduced in $12 \% \mathrm{NaOH}$ solution for $1 \mathrm{~h}$ at room temperature. Finally, they are treated in the steam of $1 \mathrm{M} \mathrm{HCl}$ for $30 \mathrm{~min}$. Fig. 1b. After cutting it was observed that the dominant length is $10 \mathrm{~mm}$ (Fig. 1c), and the diameter is varying from 40 to $80 \mu \mathrm{m}$ (Fig. 1d).

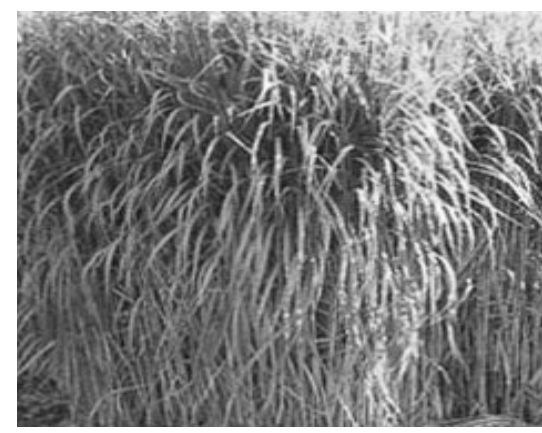

(a)

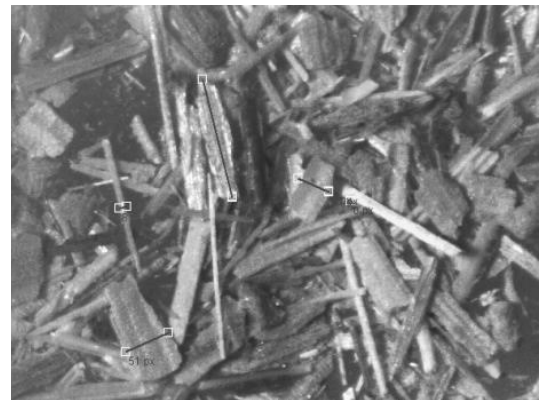

(c)

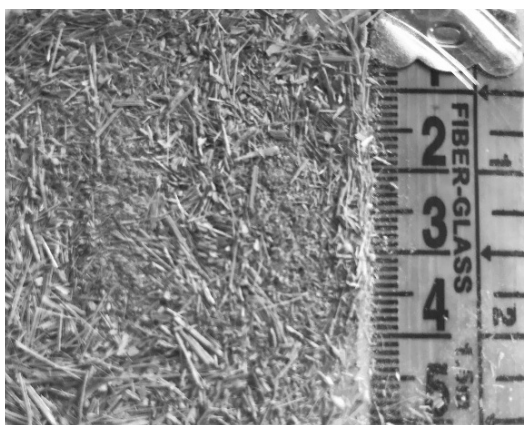

(b)

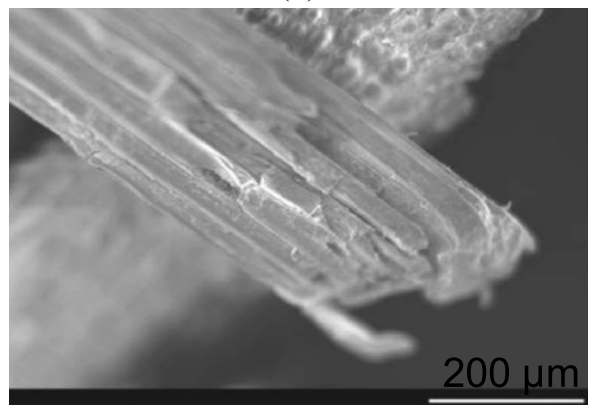

(d)

Figure 1. Miscanthus: a) plan, b) treated fiber, c) M observations of cut fibers, and d) morphology of the fiber. 


\section{DEVELOPMENT OF THE FRICTION COMPOSITES}

The investigated friction composites are derived from an industrial formulation used for automotive applications, comprising binder resin, friction modifiers and space filler. Compared to the industrial formulation, the number of ingredients of the studied material will be reduced to five in order to limit synergistic effects of composition and manufacturing process, and with the aim of a better understanding of Miscanthus fiber's impact on braking and wear performances. Detailed formulation is given in Table 1. Modified formulations are developed by adding Miscanthus fiber, in weight percent, which replaced equal quantities of filler. Formulation containing 5, 10, and 15 $\mathrm{Wt} \%$ of Miscanthus is designed, respectively Mat1, Mat2 and Mat3. Friction material specimens are produced by a conventional procedure for a dry formulation following dry-mixing, pre-forming and hot pressing (Table 2). For all the components, an appropriate amount is mixed using an electric blender for $10 \mathrm{~min}$. The resulting mixture is molded for production of the brake pad samples for $10-15 \mathrm{~min}$ at $150^{\circ} \mathrm{C}$ under a pressure of $150 \mathrm{MPa}$ by a hot-press. Brake pad samples produced are held in an oven at $200^{\circ} \mathrm{C}$ for 4 hours for post-curing. A specific punch-matrix has been developed for brake lining materials elaboration (Fig. 2a). Full size lining material with a weight of $80 \mathrm{~g}$ is used for performance test, and small samples with a weight of $4 \mathrm{~g}$ are used for microstructural analysis (Fig. $2 \mathrm{~b}$ ).

Table 1. Composition of the developed materials ( $\mathrm{Wt} \%)$.

\begin{tabular}{|c|c|c|c|c|c|}
\hline \multirow{2}{*}{ Sample } & Fiber & Friction modifier & Abrasive & Binder & Filler \\
\cline { 2 - 6 } & Miscanthus & Cashew & Alumina & Phenolic Resin & $\begin{array}{c}\text { Barite and Calcium } \\
\text { carbonate }\end{array}$ \\
\hline Mat1 & 5 & 25 & 10 & 15 & 45 \\
\hline Mat2 & 10 & 25 & 10 & 15 & 40 \\
\hline Mat3 & 15 & 25 & 10 & 15 & 35 \\
\hline
\end{tabular}

Table 2. Procedure and conditions of the green composite elaboration.

\begin{tabular}{|c|l|l|}
\hline S. No. & Procedure & Conditions \\
\hline 1 & $\begin{array}{l}\text { Sequential mixing in } \\
\text { Plough-Shear mixer }\end{array}$ & $\begin{array}{l}\text { Total duration } 10 \text { minutes shovel } 140 \mathrm{rpm} \text { Cutter Speed } 3000 \mathrm{rpm} \\
\text { and 3 kg mix is prepared } \\
\text { Sequence: (a) Fibers (b) Powdery Ingredients (c) Binders }\end{array}$ \\
\hline 2 & Hot molding & $\begin{array}{l}\text { Temp. } 150^{\circ} \mathrm{C} \text {; compression pressure } 50 \mathrm{MPa} \text {; the cavity is filled } \\
\text { with approximately } 80 \text { grams of the mixture }\end{array}$ \\
\hline 3 & Curing & Curing time: $6 \mathrm{~h}$, curing temp. $160^{\circ} \mathrm{C}$ \\
\hline 4 & Finishing & $\begin{array}{l}\text { Gridding is done to remove the resin layer and burs and a center } \\
\text { cut is given to enhance air circulation during braking as well as } \\
\text { to remove worn debris during braking }\end{array}$ \\
\hline
\end{tabular}

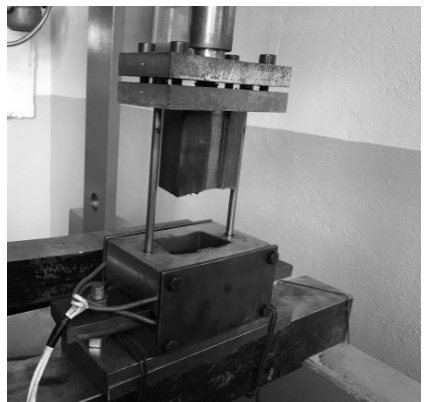

(a)

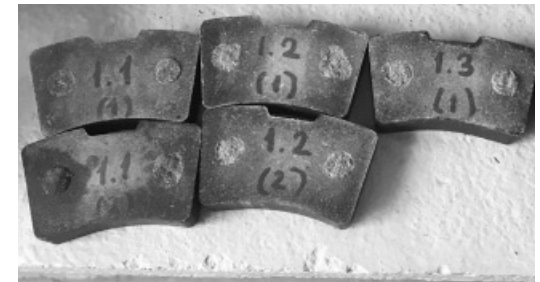

(b)

Figure 2. a) Developed punch-matrix to prepare b) brake pad specimens. 


\section{CHARACTERIZATION OF THE DEVELOPED COMPOSITE MICROSTRUCTURAL, PHYSICAL, AND MECHANICAL CHARACTERIZATION}

To characterize the developed composites, several tests were conducted. Specific gravity characterization was measured by an apparatus that works on the Archimedes principle using JIS-D-4418 standard. Hardness was studied according to IS 2742 Part-3 standard and using the K scale having a steel ball indenter of $3.125 \mathrm{~mm}$ diameter, and a load of $1500 \mathrm{~N}$ was applied. The test was conducted on a Soxhlet extraction apparatus as described by Thiyagarajan et al. (2015), on a prismatic sample. The shear strength was done at normal room temperature. The test is conducted based on ISO 6312 Standard. To characterize the material porosity, a sample with the size of $25 \mathrm{~mm}$ x $25 \mathrm{~mm}$ was placed in a desiccator for 24 hours, then it was soaked in a pre-heated SAE 90 -grade oil bath at $90^{\circ} \mathrm{C} \pm 1{ }^{\circ} \mathrm{C}$ for 8 hours. After a simulated time, the heater was turned off and the sample was cooled in the ambient temperature. This test was in accordance with the JIS D 4418 standard.

\section{LABORATORY FADE-RECOVERY TEST}

Fade-recovery tests were carried out using Chase friction test rig, composed of seven test sequences, in accordance with IS 2742 Part-4 Standard as described in Manoharan et al. (2019). A Gray Cast iron disc of automobile (280 mm diameter) was used as the antagonist material. Weight loss and density data were used to calculate the wear volume of the composites. Test specimen was conditioned by burnishing for $20 \mathrm{~min}$ at a speed of $306 \mathrm{rpm}$, a load of $45 \mathrm{bar}$ and a maximum temperature of $93^{\circ} \mathrm{C}$ to ensure at least $95 \%$ of the apparent surface between the pad and the disc. Specimen was reset by running at 23 bar and $205 \mathrm{rpm}$ for $5 \mathrm{~min}$. After a baseline test, fade test is conducted with 67 bar at $411 \mathrm{rpm}$. Just after that, the pad sliding to generate a heating by friction up to $289^{\circ} \mathrm{C}$, to characterize the fade behavior at hot temperature. This temperature is controlled by thermocouple glued 2 millimeters from the pad-disc contact surface. To qualify how quickly a friction material can recover to base line characteristics of friction level, a recovery test is applied and carried out immediately after the fade test, for which the drum could cool while rotating. The temperature decreased from $260^{\circ} \mathrm{C}$ to $93^{\circ} \mathrm{C}$. Wear runs without any modification of speed and load. It was run at a drum temperature between $193^{\circ} \mathrm{C}$ and $205^{\circ} \mathrm{C}$ then followed with the load applied for $20 \mathrm{~s}$ and then removed for 100 applications. Secondary fade and recovery tests are achieved to better study the resistance to friction at different temperature levels under standard braking conditions. The deduced parameters from these friction tests are

- Normal coefficient of friction $\left(\mu_{\text {normal }}\right)$ was calculated as the average of selected $\mu$ values. In our case, it is corresponding to $95,110,136,161,188$ and $214^{\circ} \mathrm{C}$ from Fade 2 cycles.

- $\mu$-Minimum $\left(\mu_{\min }\right)$ : this is the lowest coefficient of friction in all the studied modes (baseline, fade and recovery) (higher, the better).

- $\mu$-Maximum $\left(\mu_{\max }\right)$ : this is the highest coefficient of friction in all three modes (lower, the better).

- Friction variation $(\Delta \mu)$ : difference between $\mu_{\max }$ and $\mu_{\min }$ collected from the $\mathrm{m}$ values of baseline, fade and recovery cycles (lower, the better).

- $\quad \mu$ Performance $\left(\mu_{\text {perf }}\right)$ : average of $\mu$ taken after $1 \mathrm{~s}$ for fade and recovery cycles at a temperature greater than $100^{\circ} \mathrm{C}$ (higher, the better).

- $\quad \mu_{\text {fade }}$ : minimum coefficient of friction for fade mode, measured after $235^{\circ} \mathrm{C}$ (lower, the better).

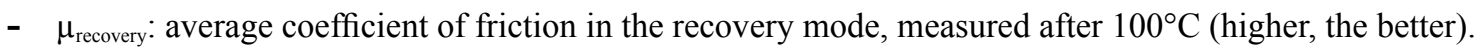

To quantify the wear rate (\%), the thickness and weight of each specimen's wear were measured before and after test, using digital sensors. 


\section{RESULTS AND DISCUSSION MICROSTRUCTURAL ANALYSIS}

The microstructure of the polished cross-sectional surface of the new developed materials is studied by optical microscopy, Fig. 3. Materials (indicated by Mat1, Mat2 and Mat3) consist of compounds of dimensions varying from millimeter to tenth of millimeter. The complexity of this proprietary green material is well shown in the mixture of vegetable constituents and nonnatural particles and fiber within a polymeric binder.
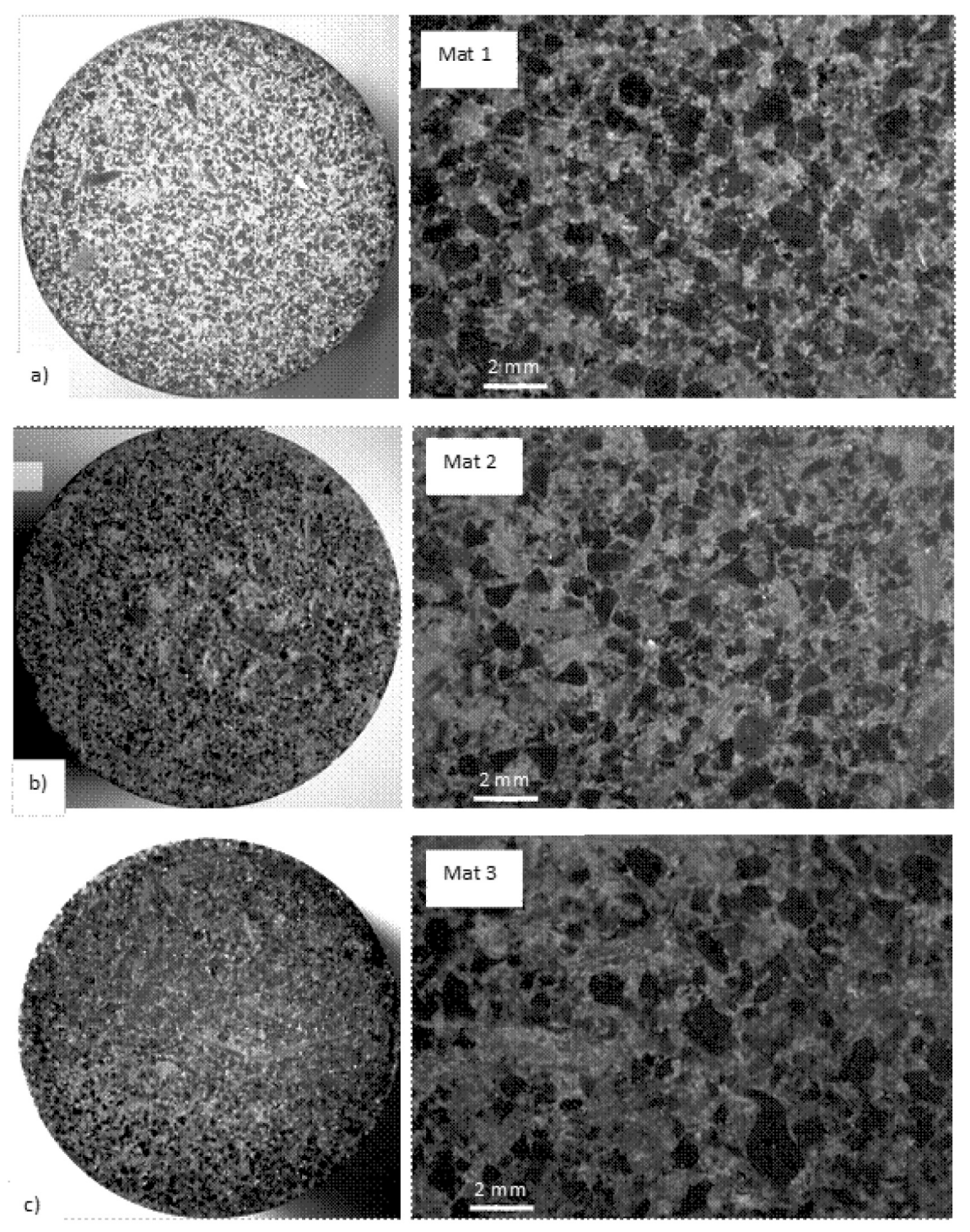

Figure 3. Microstructures of the 3 developed composites: a and a') Mat1, b and b') Mat2, c and c') Mat3.

From Figs. 3a, b and c, it is clearly visible that the samples present more percentages of fillers (Barite and Calcium carbonate). Cashew powder has the dominant size compared to other used particles. It has different shapes (spherical, triangular, aleatoric, ...), with a diameter that can reach some millimeters. However, the Miscanthus fibers, spread on the surface, have the biggest length, clearer in Mat3 surface, having a mean size of $3 \mathrm{~mm}$ (Brown elements). As the $w t \%$ of the fibers increases, moving from Mat1 to Mat3, there is more uniform distribution of these. At the magnification applied in Figs. 4b' and 4c', Miscanthus fiber is shown to be well incorporated within the binder. It 
has a preferential orientation, in the parallel direction of the rubbing surface. However, some bundles of fiber have remained. Hentati et al. (2014) demonstrated that this topography is well influenced by the rearrangement of fibers and particles during cold pre-forming and hot molding phases. Despite the burnishing phase of polishing to obtain a glass surface necessary for microscopic observation, no holes are detected, which confirms a good adhesion between the treated natural and artificial elements. SEM observations of the developed materials show a good interface between the bunder and the other ingredients, particularly the green fiber (Fig. 4).

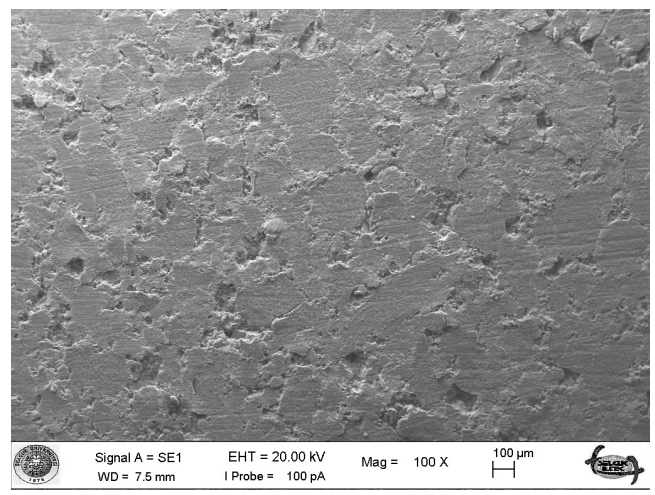

a)

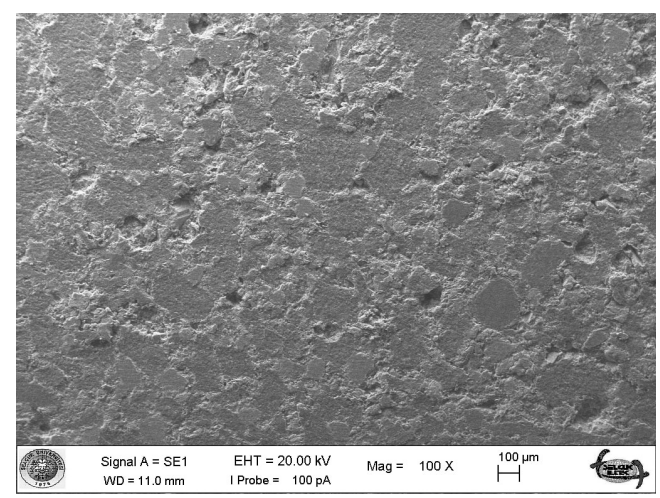

b)

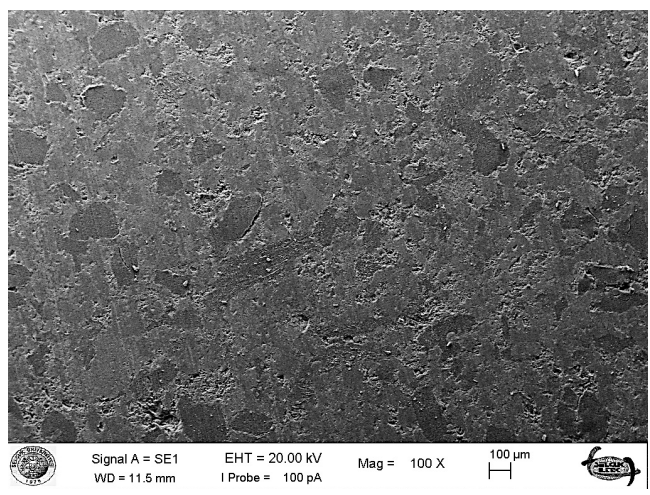

c)

Figure 4. SEM observations of the a) Mat1, b) Mat2, and c) Mat3 microstructures.

\section{PHYSICAL AND MECHANICAL PROPERTIES}

The most important physical and mechanical properties that influence the friction-wear behavior of friction composite materials are identified (Table 3). Results show that 5\% Miscanthus fiber material has the highest density. It can be attributed to the generated space between ingredients (not voids) leading to reduced density. In many cases of green friction materials, similar trends are noticed (14\% banana fiber friction material $\left(1.8 \mathrm{~g} . \mathrm{cm}^{-3}\right), 15 \%$ sisal fiber friction material $\left(1.86 \mathrm{~g} . \mathrm{cm}^{-3}\right), 8 \%$ micro-cellulose fiber $\left(1.835{\mathrm{~g} . \mathrm{cm}^{-3}}^{-3}\right.$ as reported by Bashir et al. (2019), Wei et al. (2015) and Marewad et al. (2018) respectively). These results are also comparable to several industrial formulations $\left(1.81 \mathrm{~g} . \mathrm{cm}^{-3}\right.$ as indicated in the work of Hentati et al. (2014) for European production, $1.9 \mathrm{~g} . \mathrm{cm}^{-3}$ as reported by Kchaou et al. (2017) for Malaysian production). In terms of mechanical behavior, Mat3 shows the best mechanical properties. An adding of $10 \%$ of Miscanthus fiber relative to Mat 1 induces an improvement of $8 \%$ on the shear-compression modulus. When they use 6,10 and 16\% cellulose fiber, Marewad et al. (2018) found a maximum 105.6 MPa shear compression modulus. These results confirm a better curing, which is coherent with microstructure analysis. As there are no significant gaps between Mat2 and Mat3 physical and mechanical properties, we were content to study Mat1 and Mat2 friction-performance behavior. 
Table 3. Density and shear-compression modulus values of the 3 developed friction materials (the standard deviation and the number of tests are indicated in parentheses).

\begin{tabular}{|c|c|c|}
\hline Sample & Density $\left(\mathbf{g . c m}^{-3}\right)$ & $\begin{array}{c}\text { Shear-compression } \\
\text { modulus (MPa) }\end{array}$ \\
\hline Mat1 & $1.9(0.1 / 5)$ & $300(5.2 / 5)$ \\
\hline Mat2 & $1.8(0.12 / 5)$ & $320(4.1 / 5)$ \\
\hline Mat3 & $1.7(0.11 / 5)$ & $322(5.7 / 5)$ \\
\hline
\end{tabular}

\section{TRIBOLOGICAL BEHAVIOR}

Fig. 5 shows typical performance results of Mat 1 and Mat2. It is noticed that Mat2 showed a higher coefficient of friction at the initial stage, which increased from 0.49 to 0.56 after 10 cycles rubbing (Fig. 5a). However, the values of coefficient of friction for Mat 1 are considered acceptable and in accordance with previous literatures, which developed eco-friendly friction composites based on banana fiber (0.44) (Idris et al., 2015) and maize husks (0.45) (Ademoh et al., 2015). Another element that impacted the coefficient of friction during baseline is the presence of Calcium Carbonate as small amorphous crystallites. In fact, Mat1 composition is rich with Calcium Carbonate with $45 \mathrm{wt} \%$, which boosts the friction. Therefore, the coefficient of friction at the final baseline is more important that Mat2: it does not drop below 0.39, whereas, for Mat2, it reached 0.31 (Fig. 5b). As confirmed by Persson (2001) and Sandeep et al. (2018), the higher the shear modulus, the upper the coefficient of friction. Fig. 5c shows the friction evolution under 100 cycles. For both materials, the coefficient of friction is above 0.35 . Figs. $5 \mathrm{~d}$ and $5 \mathrm{f}$ illustrate the friction behavior of Mat 1 and Mat 2 with the increase in the temperature level, up to the degradation of the phenolic resin matrix (about $300-350^{\circ} \mathrm{C}$ ). It was noticed that the coefficient of friction is globally equal to 0.35 without any noticeable difference between the two materials. However, compared to the friction at room temperature, this coefficient is reduced by inducing what is called thermal fade. This characteristic is extremely important to qualify the braking performance of a developed material. On the other hand, the fade 1 rate is more significant than the second fade for Mat2. Manoharan et al. (2019) attributed this behavior to the formation of nucleated plateaus, which acts as abrasive elements in the sliding contact. As the coefficient of friction is well affected by the temperature Mat 1 with $5 \mathrm{wt} \%$ of Miscanthus shows acceptable fading performance, with a hot coefficient of friction compared to other ecofriendly materials developed by Rashid et al. (2017) and Matejka et al. (2013). The large fluctuation in the coefficient of friction in the second fade can be attributed to cumulative damage in the rubbed surface, induced by the concentration of heating on the surface and the loss of rigidity. Therefore, the coefficient of friction decreases to low values since the temperature reached $300^{\circ} \mathrm{C}$ with the same rate for the two materials. This temperature is critical and corresponds to the phenolic resin degradation. In fact, at this situation, polymeric materials such as rubber and friction dust are decomposed and bonded among the reduced ingredients. This phenomenon accelerates the generation of three-body sliding contact, which covered the rubbing surface. As the temperature increases at the interface, the coalescence among ingredients is affected. A dramatical reduction of the coefficient of friction is noticed. In a study conducted by Liu et al. (2018), it was found that the natural fibers could not provide enough thermo-mechanical stability for the brake lining matrix after $300^{\circ} \mathrm{C}$. Consequently, it was observed that the coefficient of friction for Mat2 drops drastically to 0.22 at $350^{\circ} \mathrm{C}$, whereas Mat1 keeps an acceptable value, about 0.26 at the same temperature.

Furthermore, there is a third stage called recovery behavior, after exhibiting severe fade behavior (Figs. 5e and $5 \mathrm{~g}$ ). Owing to the high temperature and the increasing of braking cycles, both materials softened, and a considerable amount of mentioned material was transferred. It is shown by the quick decreasing on the coefficient of friction for Mat 2 after a slight increase of the coefficient from 0.48 at $150^{\circ} \mathrm{C}$ to 0.2 at $250^{\circ} \mathrm{C}$. However, Mat 1 shows more ability to recover and keeps an acceptable coefficient of friction at the first stage of recovery, about 0.35 (Fig. 5e). After this stage, and as temperature decreased, the pad surface hardens progressively, which induces an increase in friction resistance and leads to the occurrence of the second recovery (Fig. 5g). Two transitions were noticed. Before the temperature rise to $200^{\circ} \mathrm{C}$, the coefficient of friction of the two materials increases from 0.39 to 0.41 for Mat1 and from 0.33 to 0.39 for Mat2. Then, the order of recovering ability is inversed, and Mat1 shows less resistance to the temperature without losing an acceptable and stable friction of coefficient. It was kept above 0.3. As discussed 
by Manoharan et al. (2019), the main reasons for the above changes are the effect of the alternation between frictionwear mechanisms with a competition between the formation and fracture regeneration of the second plateaus during the friction process. At high temperature, a lubricating film, which may be due to the uncarbonized Miscanthus fiber, shows a decrease of the coefficient with extremely low values, like those of checked with Mat2.

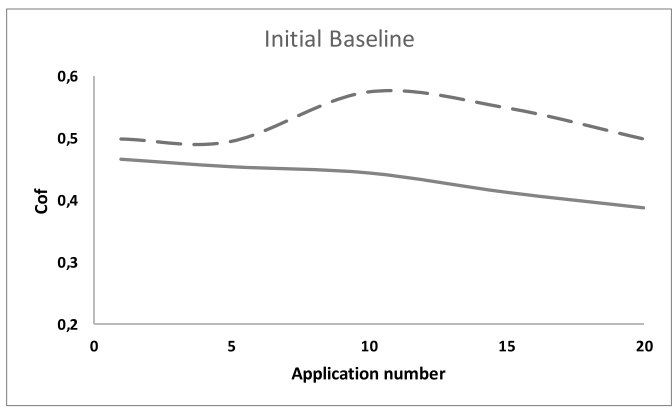

(a)

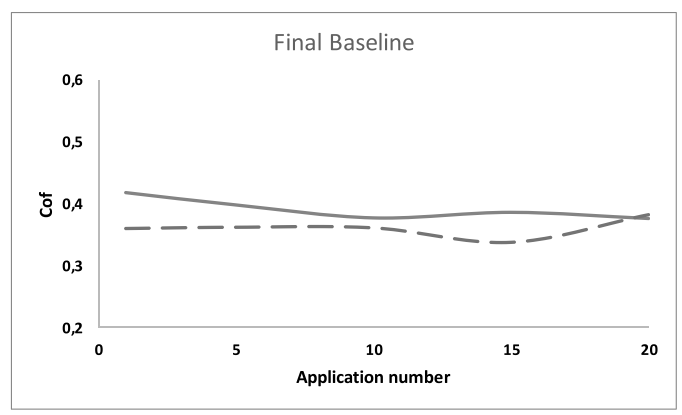

(b)

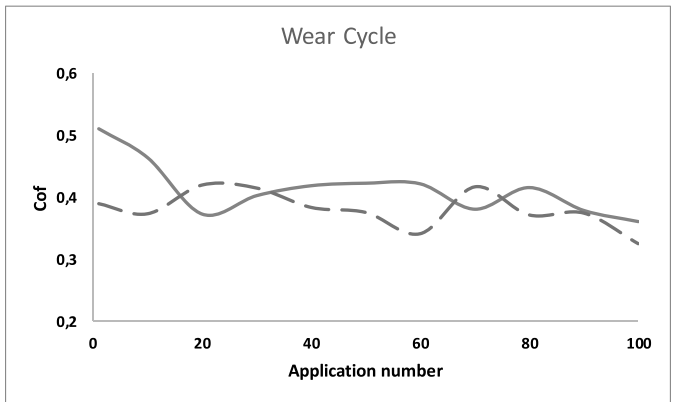

(c)

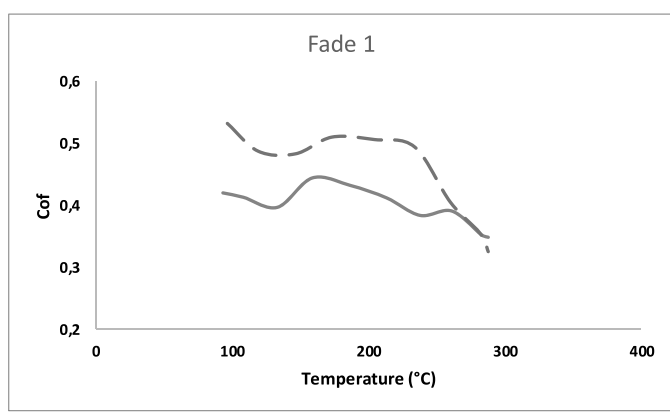

(d)

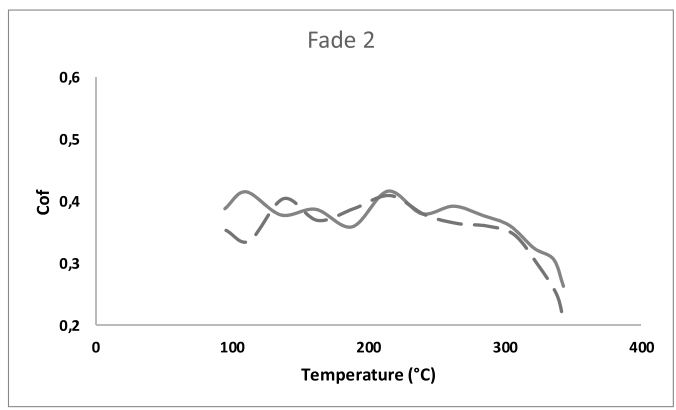

(f)

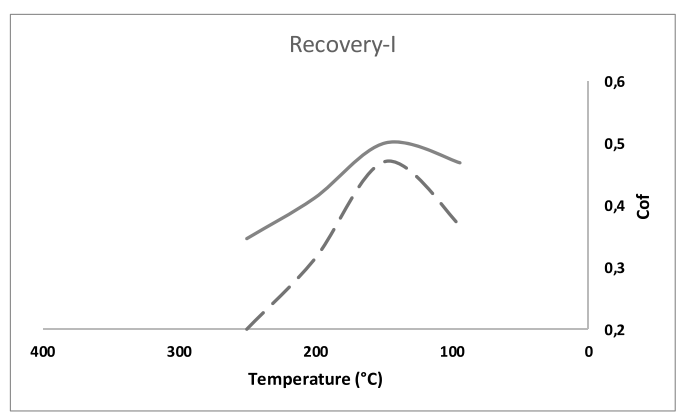

(e)

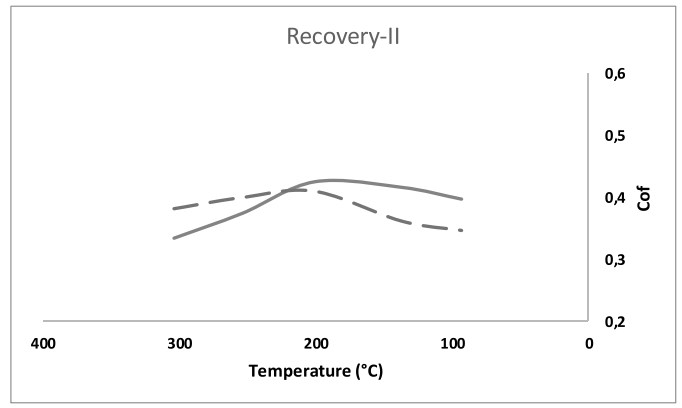

(g)

Figure 5. Performance results from Chase testing (— Mat1, - - -Mat2). 
$\mu_{\text {normal }}, \mu_{\text {perf }}, \mu_{\text {fade }}$ and $\mu_{\text {recovery }}$ for Mat1 and Mat2, respectively, equal to $(0.39 ; 0.38),(0.43 ; 0.41),(0.38 ; 0.4)$, and $(0.5$; 0.47), are summarized in Fig. 6. As $\mu_{\text {fade }}$ represents the level of friction at severe braking conditions, it is considered the most important parameters to qualify friction material for possible automotive braking application. As demonstrated by Kumar and Bijwe (2013), it should be in the range of 0.35-0.45 for automotive industrial reports. In our cases, the two developed materials show a similar trend. Friction is slightly higher in case of the $\mu_{\text {normal }}$ and $\mu_{\min }$ for Mat1, while in $\mu_{\max }$ it is less. This is in concordance with the recovery behavior of such materials. In fact, $\mu_{\text {normal }}$ is calculated as per fade cycle. This value is increased when the coefficient of friction in fade 2 increases, too. Therefore, the value is less for Mat 2 due to the high recovery of this material at high temperature as described in the below paragraph. As consequence, del $\mu$ of Mat 1 is about 0.25 and 0.3 for Mat2. However, $\mu_{\text {perf }}$, which consists of average of $\mu$ taken after $1 \mathrm{~s}$ for fade and recovery cycles at a temperature greater than $100^{\circ} \mathrm{C}$, is higher for Mat 1 . That means the presence of natural fiber does not affected the thermal resistance and the chemical stability of the friction material, i.e. less worn out and low debonding from binder which plays a critical role at high temperature.

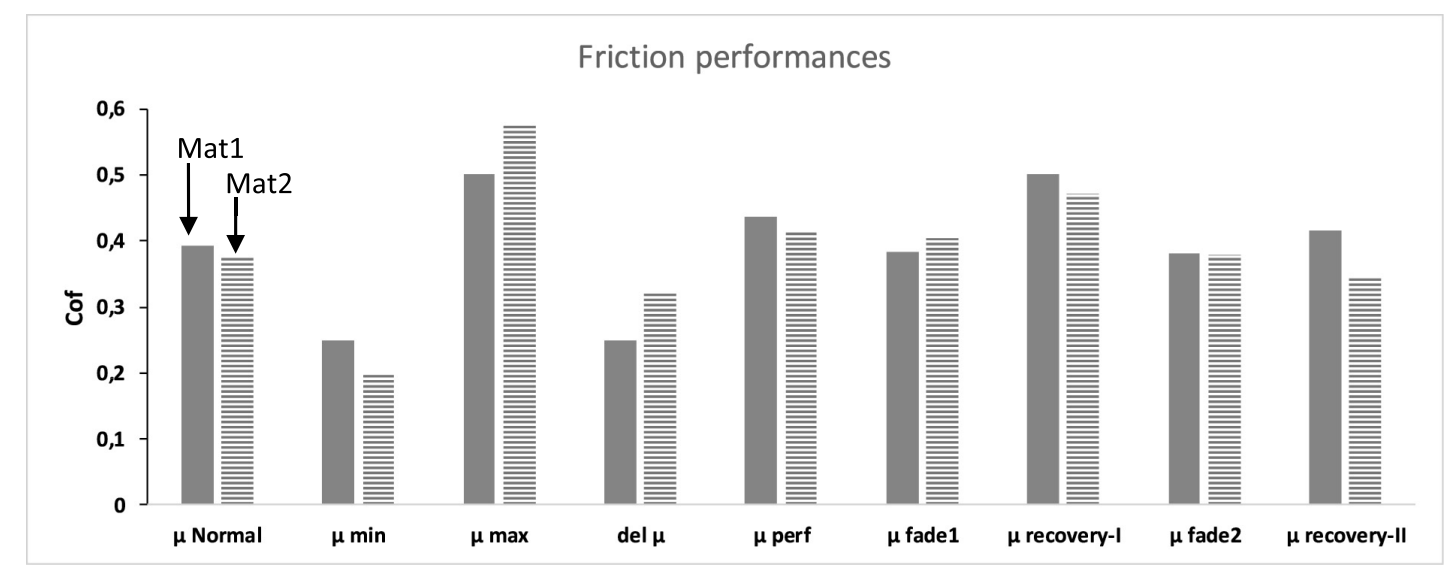

Figure 6. Friction performance indicators of the developed materials.

Fig. 7 shows fade and recovery rates of the developed materials. As reported by Kumar and Bijwe (2013), to assure the friction performance behavior of a brake material, the value of $\mu_{\text {fade }}$ should be in the range of $0-20 \%$. In our case, results are within this range, with $\mu_{\text {fadel }}(12 ; 2 \%)$ and $\mu_{\text {fade } 2}(12.8 ; 8.6 \%)$ for Mat1 and Mat2, respectively. Fade rate describes how the friction coefficient loses its quality at high temperature. The lower the fade rate percentage, the higher the fade resistance. Therefore, Mat2 shows more ability to resist to the high temperature effect. To conclude, about the ability of materials to regain its friction coefficient value upon cooling, a performance parameter called $\mu_{\text {recovery }}$ is calculated. The higher recovery rate is, the better the performance in braking situation. In our case, these values are $(115 ; 95.4 \%)$ and $(108.25 ; 79.5)$ for Mat1 and Mat2, respectively. There are no significant differences between the developed materials. Stapathy and Bijwe (2004) demonstrated that the surface topography and the porosity play a decisive role on the recovery rate of a brake friction material. Oluwafemi et al. (2019) reported that the use of biomass for the development of eco-friendly material should be well experimented as the chemical treatment of the new elements leading to the effective results.

The performance results of Mat2 are compared to several green friction materials as summarized in Table 4. Mat2 shows more important fading behavior compared to other green friction materials made from Palm Kernel Shell Particles (Koya et al., 2010), or Crab shell powder (Lenin et al., 2019) or Jute fiber and powdered hazelnut shells (Matějka et al., 2013) or Promaxon-D (Mahale et al., 2019) or Natural graphite (Kolluri et al., 2010), but less resistance to recovery phenomenon compared to jute-based brake materials. To mitigate such effects, the formulation based on Miscanthus fiber should be optimized, particularly in the choice of volume fraction. The nature and the type of resin may be also taken into consideration to improve performance. However, this comparison makes the use of Miscanthus more encouraging than other green ingredients. 


\section{Fade and recovery rate (\%)}

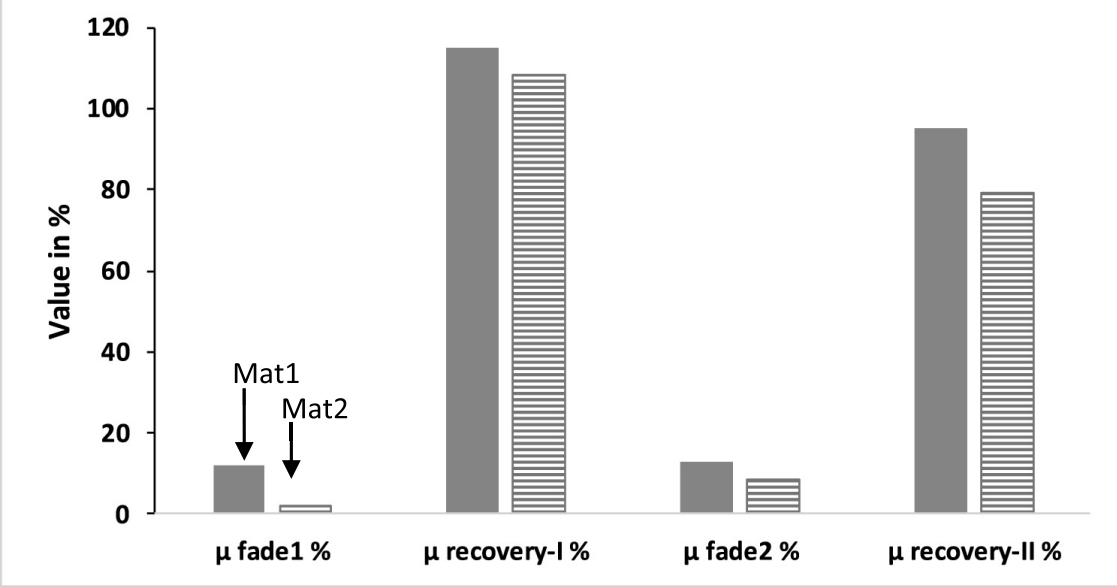

Figure 7. Fade and recovery rates values.

Table 4. Experimental results compared with several developed green friction materials taken from literature.

\begin{tabular}{|c|c|c|c|c|c|c|}
\hline Parameters & Mat2 & $\begin{array}{c}\text { Palm Kernel } \\
\text { Shell Particles } \\
\text { (Koya et al., } \\
\text { 2010) }\end{array}$ & $\begin{array}{c}\text { Jute fiber and } \\
\text { Crab shell } \\
\text { powder (Lenin } \\
\text { et al., 2019) }\end{array}$ & $\begin{array}{c}\text { powderized } \\
\text { hazelnut shells } \\
\text { (Matějka et al., } \\
\text { 2013) }\end{array}$ & $\begin{array}{c}\text { Promaxon-D } \\
\text { (Mahale et al., } \\
\text { 2019) }\end{array}$ & $\begin{array}{c}\text { Natural } \\
\text { graphite } \\
\text { (Kolluri et al., } \\
\text { 2010) }\end{array}$ \\
\hline$\mu_{\text {perf }}$ & 0.41 & 0.35 & 0.38 & 0.4 & 0.473 & 0.353 \\
\hline$\mu_{\text {fade }}$ & 0.4 & 0.3 & 0.32 & 0.3 & 0.31 & 0.324 \\
\hline$\mu_{\text {recovery }}$ & 0.47 & 0.55 & 0.35 & 0.6 & 0.38 & 0.383 \\
\hline
\end{tabular}

Mat 2 shows more wear phenomenon with a weight loss about 5\% compared to Mat 1 with only $4 \%$. These values are not considered higher when we compare to other developed green friction materials developed by Idris et al. (2015) (using $15 \%$ banana peels $4.67 \%$, using $10 \%$ bagasse $4.2 \%$ ). When we link these results to the coefficient of friction, we conclude that the higher the coefficient, the lower the wear rate, in concordance with most brake lining materials characteristics. These values are aligned with the findings of Ruzaidi et al. (2011), where optimal composition using natural fiber is developed with the compromise friction-wear and mechanical resistance.

\section{CONCLUSION}

The influence of the incorporation of Miscanthus fiber was conducted to study the possible development of natural fiber-based friction composites, and it was found that:

- A good interfacial bonding between Miscanthus fiber and the phenolic resin was noticed.

- The adding of Miscanthus fiber with $10 \mathrm{wt} \%$ or more gives the best physical, mechanical, and microstructure properties which are comparable to the commercial formulation. No gap between $10 \mathrm{wt} \%$ and $15 \mathrm{wt} \%$ adding fiber was noticed.

- The 5\% Miscanthus fiber-based materials have shown less fade, high recovery, and less wear rate.

- Miscanthus fiber can be successfully incorporated into industrial formulation for possible development of brake 
material, as it has given stable and high friction coefficient and wear resistance at high temperature for moderate level of energy. An optimization study should be investigated to determine a suitable composition for industrial service.

- A graphical abstract is shown in the following schema. As perspective, a statistical study can be investigated to clarify possible uncertainties in our work.
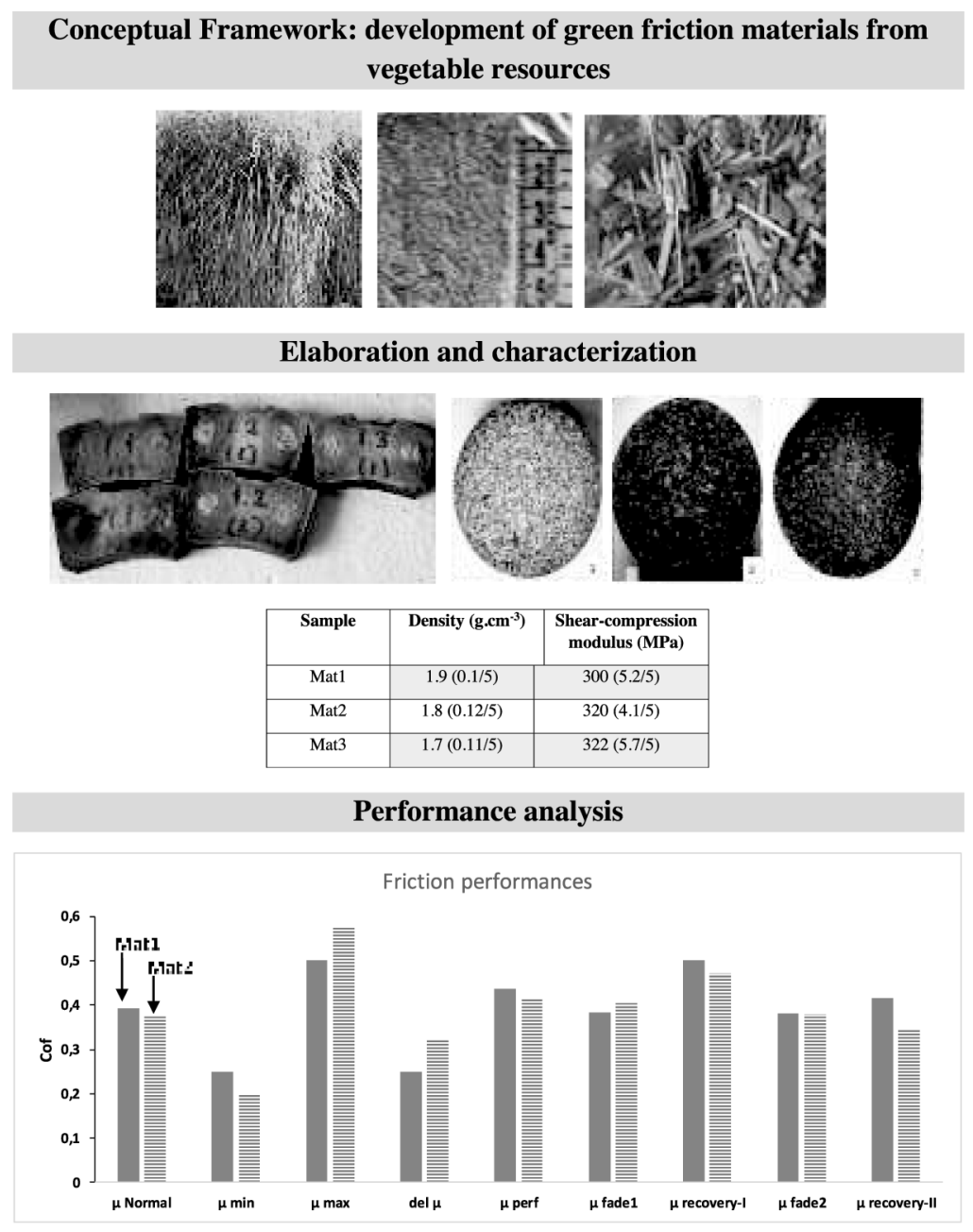

\section{ACKNOWLEDGMENT}

The authors gratefully acknowledge the support of the University of Bisha (KSA), Scientific Research Projects coordinatorship of Selcuk University, MERS Tunisia through the project 18PJEC12-17, National Institute of Technology and Surya Engineering College Mettukadai, India.

\section{REFERENCES}

Ademoh, N.A. and Olabisi, A.I., 2015. Development and evaluation of maize husks (asbestos free) based brake pad. Industrial Engineering Letters, 5: 67-80.

Aranganathan, N., and Bijwe, J., 2016. Comparative performance evaluation of NAO friction materials containing natural graphite and thermographite. Wear, 358-359: 17-22. 
Bashir, M., Qayoum, A., Saleem, S.S., 2019. Influence of lignocellulosic banana fiber on the thermal stability of brake pad material. Materials Research Express, 6(11): 1-15.

Hentati, N., Kchaou, M., Cristol, A.L., et al., 2014. Impact of post-curing duration on mechanical, thermal and tribological behavior of an organic friction material. Materials and Design, 63: 699-709.

Ibhadode, A.O.A., Dagwa, I.M., 2008. Development of asbestos-free friction lining material from palm kernel shell. J. Braz. Soc. Mech. Sci. Eng., 1(1): 1-2.

Ibhadoe, A.O.A., and Dagwa, I.M., 2008. Development of asbestos-free friction lining material from palm kernel shell. J. Braz. Soc. Mech. Sci. \& Eng., 30(2): 166-173.

Idris, U.D., Aigbodion, V.S., Abubakar, I.J., Nwoye, C.I., 2015. Eco-friendly asbestos free brake-pad: using banana peels. J. King Saud Univ.-Eng. Sci., 27(2): 185-192.

Ige Oluwafemi, E., Inambao Freddie L., and Adewumi Gloria, A., 2019. Biomass-based composites for brake pads: a review. International Journal of Mechanical Engineering and Technology, 10: 920-943.

Jan, E.G., 2008, 20 October. Environmental benefits of natural fiber production and use, Proceedings of the Symposium on Natural Fibers, Rome - Italy.

Kabir, M.M., Wang, H., Lau, K.T., Cardona, F., 2012. Chemical treatments on plant-based natural fiber reinforced polymer composites: An overview. Composites: Part B, 43: 2883-2892.

Kchaou, M., Mat Lazim, A.R., Abdul Hamid, M.K., Abu Bakar, A.R., 2017. Experimental studies of friction-induced brake squeal: Influence of environmental sand particles in the interface brake pad-disc. Tribology International, 110: 307-317.

Koya, O.A., and Fono, T.R, 2010, 1-3 February. Palm kernel shell in the manufacture of automotive brake pad, Conference: International Seminar on Harnessing Natural Resources for National Development, Raw Materials Research \& Development Council, Abuja, Nigeria.

Kolluri, D.K., Ghosh, A.K., Bijwe, J., 2010. Performance Evaluation of Composite Friction Materials: Influence of Nature and Particle Size of Graphite. Journal of Reinforced Plastics and Composites, 29(18): 2842-2854.

Kumar, M. and Bijwe, J., 2013. Optimized Selection of Metallic Fillers for Best Combination of Performance Properties of Friction Materials: A Comprehensive Study. Wear, 303: 569-583.

Lenin Singaravelu, D., Rahul Ragh, M., Vijay, S.R., Manoharan. and Kchaou, M., 2019. Development and Performance Evaluation of Eco-Friendly Crab Shell Powder Based Brake Pads for Automotive Applications. International Journal of Automotive and Mechanical Engineering, 6(2): 6502-6523.

Liu, Y., Ma, Y., Che, J., et al., 2018. Natural fiber reinforced non-asbestos organic non-metallic friction composites: effect of abaca fiber on mechanical and tribological behaviour. Materials Research Express, 5: 1-25.

Matějka, V., Fu, Z., Kukutschová, J., Qi, S., et al., 2013. Jute fibers and powderized hazelnut shells as natural fillers in nonasbestos organic non-metallic friction composites. Materials \& Design, 51: 847-853.

Matejka, V., Fu, Z., Kukutschová, J. et al., 2013. Jute fibers and powderized hazelnut shells as natural fillers in non-asbestos organic non-metallic friction composites. Materials \& Design, 51: 847-853.

Marewad, D.S., Pal Singh, G., Adivarekar, R.V., 2018. Asbestos free brake pad using Micro cellulose fiber for automotive industry, International Journal of Advance Research. Ideas and Innovations in Technology, 4: 685-690.

Mahale, V., Bijwe, J., Sinha, S., 2019. Efforts towards green friction materials. Tribology International, 136: 196-206.

Manoharan, S., Vijay, R., Lenin Singaravelu, D., Kchaou, M., 2019. Experimental Investigation on the Tribo-Thermal Properties of Brake Friction Materials Containing Various Forms of Graphite: A Comparative Study. Arabian Journal for Science and Engineering, 44: 1459-1473.

Morshed, M.M., and Haseeb, A.S.M.A., 2004. Physical and chemical characteristics of commercially available brake shoe lining materials: a comparative study. Journal of Materials Processing Technology, 155-156: 1422-1427.

Namessan, N.O., Maduako, J.N., Iya, S.A., 2013. Comparative study of the effects of treatment techniques on the thermal, friction and wear properties of kenaf (Hibiscus cannabinus) fiber reinforced brake pads. African Journal of Science and Technology (AJST), Science and Engineering Series, 12(2): 44-54. 
Parandaman, P., Jayaraman, M., Ramasamy, K.K., Premkumar, M., 2015. Mechanical Performance of Coir and Glass Fibre Reinforced Hybrid composite materials for Automotive Brake Pad. International Journal of Applied Engineering Research, 10(32): 1-13.

Persson, B.N.J., 2001. Theory of rubber friction and contact mechanics. Journal of Chemical Physics, 11: 3840-3861.

Pujari, S., and Srikiran, S., 2019. Experimental investigations on wear properties of Palm kernel reinforced composites for brake pad applications. Defense Technology, 15(3): 295-299.

Rashid, B., Leman, Z., Jawaid, M., et al., 2017. Eco-Friendly Composites for Brake Pads From Agro Waste: A Review. Reference Module in Materials Science and Materials Engineering, 1: 1-21.

Ruzaidia, C.M., Kamarudin, H., Shamsul, J.B., Abdullah, M.M.A., 2011. Comparative Study on Thermal, Compressive, and Wear properties of Palm Slag Brake Pad Composite with Other Fillers. Advanced Materials Research, 328-330: 1636-1641.

Satapathy, B.K. and Bijwe, J., 2004. Performance of friction materials based on variation in nature of organic fibers Part I. Fade and recovery behavior. Wear, 257: 573-584.

Sai Balaji, M.A., and Kalaichelvan, K., 2013. Optimization of Organic Fibres\% [Kevlar/Arobocel/Acrylic] in NAO Brake Pad Application and its Effect on Thermal Stability \& Friction Characteristics. Key Engineering Materials, 531-532: 8-12.

Sandeep, C.S. and Senetakis, K., 2018. Effect of Young's Modulus and Surface Roughness on the Inter-Particle Friction of Granular Materials. Materials, 11: 1-10.

Shalwan, A., Yousif, B.F., 2013. In state of art: Mechanical and tribological behaviour of polymeric composites based on natural fibers. Mater Des, 48: 14-24.

Thiyagarajan, V., Kalaichelvan, K., Srinivasan, K., Venugopal, R.S., 2015. Influence of specific heat capacity on hybrid non asbestos brake pad formulation. Journal of Balkan Tribological Association, 21(1): 102-119.

Venkatesh, S., and Murugapoopathiraja, K., 2019. Scoping Review of Brake Friction Material for Automotive. Materials Today: Proceedings, 16(2): 927-933.

Wahlstrom, J., Olander, L., Olofsson, U., 2012. A pin-on-disc study focusing on how different load levels affect the concentration and size distribution of airborne wear particles from the disc brake materials. Tribol. Lett., 46: 195-204.

Wei, C., Zeng, M., Xiong, X., et al., 2015. Friction Properties of Sisal Fiber/Nano-Silica Reinforced Phenol Formaldehyde Composites. Polymer Composites, 10: 433-438. 